\title{
Realistic Adhesion Test for Photovoltaic Modules Qualification
}

\author{
Jiang Zhu ${ }^{(0)}$, Dan Wu, Daniel Montiel-Chicharro, Thomas R. Betts, and Ralph Gottschalg ${ }^{(\mathbb{1}}$
}

\begin{abstract}
Adhesion requirements for photovoltaic modules to ensure reliability are often discussed but not well defined, neither in terms of tests nor actual requirements. This paper presents a new approach for realistic assessment of the adhesion strength, which shows the conventional peel test may not ensure reliability. The test presented reproduces the actual adhesion requirements for fielded modules much more closely than the commonly used peel testing. The test is conducted in situ during standard damp-heat test at a temperature of $85{ }^{\circ} \mathrm{C}$ and $85 \%$ relative humidity, with the modules installed at an angle to give an appropriate force vector perpendicular to the backsheet. This is achieved by attaching weights to the back of the tested samples which are mounted with a $45^{\circ}$ angle on a testing rack in the environmental cabinet. With an appropriate weight holder, this could be done as part of the standard damp-heat cycle during certification and would not involve additional testing time nor significant changes in the commonly used racking. This approach will identify the weakest interface of the multilayer encapsulation system. A number of test-to-fail bespoke samples are tested to set realistic fail criteria. It is shown that the test allows discrimination between different samples and can identify unsuitable production processes.
\end{abstract}

Index Terms-Adhesion, backsheet, certification, damp-heat, delamination, EVA, in situ, peel, qualification.

\section{INTRODUCTION}

$\mathbf{T}$ HE reliability and durability of photovoltaic (PV) modules is the key to the financial success of any PV installation. PV modules rely on packaging materials to provide extended protection for solar cells and electrical circuitry against various operating environments in order to maintain long service life. Delamination is a major failure mode as, e.g., SolarWorld showed that over $90 \%$ of the modules returned have delamination-related failures [1] and there is no reason to believe that this is limited to the particular manufacturer. The prevalence of this failure mode also demonstrates that current certification practice is not sufficient to capture this issue. The peel test currently being used for

Manuscript received July 13, 2017; revised October 23, 2017; accepted November 1, 2017. Date of publication December 11, 2017; date of current version December 20, 2017. This work was supported in part by the U.K. Engineering and Physical Science Research Council through U.K.-India joint projects Stability and Performance of Photovoltaics under Grant EP/H040331/1 and in part by Joint U.K.-India Clean Energy Centre under Grant EP/P003605/1. (Corresponding author: Jiang Zhu.)

The authors are with the Centre for Renewable Energy Systems Technology, Wolfson School of Mechanical, Electrical and Manufacturing Engineering, Loughborough University, Loughborough LE11 3TU, U.K. (e-mail: J.Zhu@lboro.ac.uk; D.Wu@lboro.ac.uk; D.A.Montiel-Chicharro@lboro.ac.uk; T.R.Betts@lboro.ac.uk; R.Gottschalg@lboro.ac.uk).

Color versions of one or more of the figures in this paper are available online at http://ieeexplore.ieee.org.

Digital Object Identifier 10.1109/JPHOTOV.2017.2775149

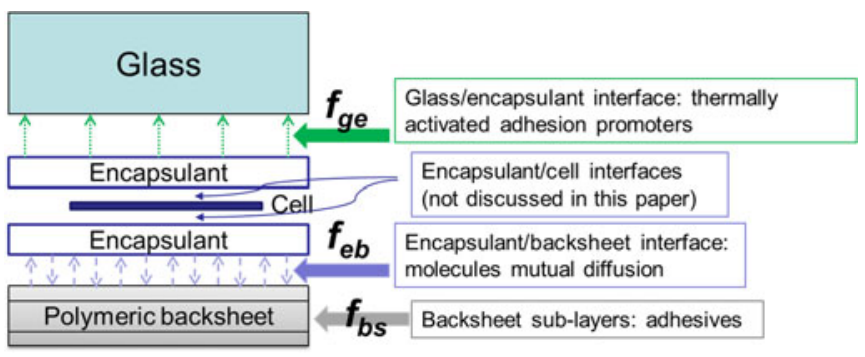

Fig. 1. Structure of a c-Si wafer-based PV module and adhesion mechanisms at three interfaces investigated in this paper.

qualifying modules designs clearly is not stringent enough. In Section II, the reasons for this are discussed.

The typical module structure for $\mathrm{c}-\mathrm{Si}$ wafer-based modules is shown in Fig. 1. It uses a structural element (front glass layer), two layers of encapsulant which sandwich the active materials and a polymeric multilayer backsheet. These layers are bonded together in a laminator and framed. The different layers are bonded adhesively to each other during the lamination process. The quality of encapsulation depends on the adhesion strength at these interfaces as well as the cohesive strength of the material.

\section{Why IS DELAMINATION Not IDENTIFIED IN CERTIFICATION?}

Current certification tests employ a peel test. The force employed is either $90^{\circ}$ or $180^{\circ}$ (T-peel). Neither test reproduces realistic conditions as the fracture initiation will be different in reality as there is no sheer stress there. Modules are currently being tested in environmental chambers in vertical racks, where delamination could be initiated, for example, by the weight of the junction box. This clearly is not happening as otherwise this would be reported by test houses as a significant failure mode. The potential reasons could be that the fracture initiation is inhibited by the frame which is clamping the backsheet in place and no pull force is placed on the module. In reality, the module is installed at an angle and thus a mixture of shear and pull forces are present as shown in Fig. 2. The potential for movement in the sheer direction is limited due to the frame but the force will be present in terms of fracture initiation. Thus, the hypothesis of this paper that a combination of pull and shear forces is required and a successful test will present both to the module.

Further reasons why failures are not commonly observed in certification testing is that adhesion testing is carried out on virgin modules (i.e., unstressed) and close to room temperature. 


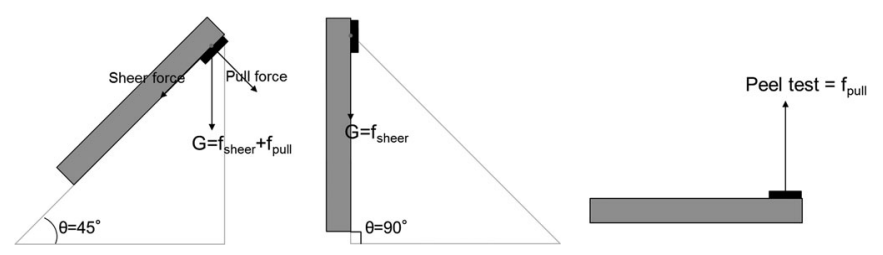

Fig. 2. Demonstration of sheer and pull forces for modules installed at different angles.

Modules regularly experience temperatures in excess of $60{ }^{\circ} \mathrm{C}$, which are above the glass transition temperatures of the most common encapsulants (EVA). Thus, the material is in a very different state when being tested in the laboratory to the real stress conditions in the field. This is critical as not only different adhesion values are obtained but also, as shown below, different failure modes may be dominant.

The differences in the forces in play and the different material state result in a lack of clarity of the adhesion strength required for fielded modules.

\section{AdHESION REQUIREMENTS FOR PV MODUlES}

\section{A. Delamination and Adhesion}

In order to avoid delamination, a minimum adhesion between different layers is required for PV modules. For EVA encapsulated modules that are tested in this study, adhesion at the EVA and backsheet interface $\left(\boldsymbol{f}_{e b}\right)$ is influenced by the primer or coupling agents added at the inner side of the backsheet. These enhance the adhesion by either forming chemical bonds or increasing physical adsorption. The inner side of the backsheet is often another layer of EVA. This allows the molecules of the two EVA layers to diffuse into each other and thus allows the backsheet manufacturer to control the adhesion of backsheet to EVA. The adhesion between EVA and glass $\left(\boldsymbol{f}_{g e}\right)$ is normally provided by thermally activated adhesion promoters [2]-[4]. The promoters are normally in the form of silane coupling agents, which are used to enhance adhesion by forming silicon-oxygen covalent bonds [5]. While the state of this is not measured directly, the gel content is still a secondary indicator as both depend strongly on the thermal history of the lamination. The backsheet of PV modules are typically multiple layers of polymers, which are bonded together with adhesives. The adhesive in between backsheet sublayers is not accessible, but could be influenced by lamination as well. Delamination may occur at the backsheet sublayers due to the degradation of adhesives $\left(\boldsymbol{f}_{b s}\right)$. Consequently, observed failures were both adhesive and cohesive depending on which interface or bulk material is the weakest one.

The adhesion requirements for reliable operation are not well understood. Failures of packaging material at interfaces of glass to encapsulant, encapsulant to backsheet, and backsheet sublayers will be investigated as these are the commonly observed failures of fielded PV modules [6]-[10] for module types that passed certification. This may be due to failure potential not being recognized in the certification test or that production modules have a variation in lamination conditions, which is known to have a significant impact on adhesion strength and retention [11].

\section{B. Issue of Variation in Lamination Temperature}

Adhesion strength at different interfaces is influenced by material properties and lamination conditions. Most material manufacturers have standard "recipes" for the lamination process, which should be closely followed to ensure durability of the product. Deviations are possible in production and this may induce a potential for delamination. Deviations are common as these can be introduced by relatively minor variations in lamination temperatures. The quality of lamination is often defined by the gel content in the encapsulant and commercially the shortest pathway to achieve the specified minimum gel content is used. This often means the highest possible temperature is chosen, where it is likely to "overshoot" and introduce negative impacts. The other extreme is manufacturers using older equipment, which sometimes may, unbeknown to themselves, not reach the specified temperatures. Therefore, variations in temperature are possible, which can directly influence adhesive strength and thus lead to differences in delamination potential. Tests are needed to distinguish between these and sieve out process conditions with increased delamination potential.

\section{Issue of Material Condition Under Test}

Adhesion deterioration that leads to failure of packaging materials is one of the crucial ageing mechanisms for PV modules. In the PV community, the peel test is widely used to characterize interfacial adhesions between glass and EVA or flexible backsheet and EVA [12]-[14]. The test is normally carried out at room condition to investigate the relative change of interfacial adhesion before and after aging. The result of adhesion tests strongly depend on the testing condition, including temperature, as e.g., elasticity of EVA is temperature dependent [15]. This is important for PV devices, where adhesion tests are carried out at room temperature but devices see much higher temperatures during operation. In maritime climates, such as the U.K., modules reach regularly in excess of $60{ }^{\circ} \mathrm{C}$ [16], while roofintegrated modules can reach $95{ }^{\circ} \mathrm{C}$ [17]. Mechanical stresses which may cause adhesion failure, e.g., the weight of junction box, unsupported cables, or cables being pulled, will be experienced at elevated temperature.

The above indicates that the stresses as well as the testing need to be carried out closer to the conditions of operation. The level of stress to be applied is not as obvious and will be investigated in the following paper. The overall stress level or the required adhesion strength is not easily defined. The requirements set today are for as produced modules. During normal operation, the adhesion strength can be reduced to less than $10 \%$ of its initial values. Thus, tests should be conducted on the aged material.

\section{DeVelopment of A Novel Test}

To address the points above, it is suggested to use a test that can be implemented during "normal" certification tests as this would minimize additional testing effort. It also has the added 

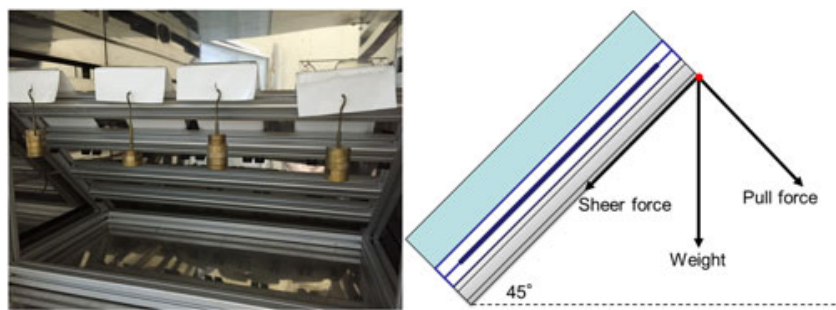

Fig. 3. DUT with weight hung from the top part of backsheet that forms a mix of pull and sheer forces.

advantage that stressing is carried out during expected aging conditions. Thus, the suggestion is to use the standard dampheat $(\mathrm{DH})$ test, where PV modules are exposed to a relative humidity of $85 \%$ at a temperature of $85^{\circ} \mathrm{C}$ for a testing period of $1000+$ hours.

The test developed in this paper is to investigate delamination of the backsheet (or other layers), not adhesion of the junction box or other components. Thus, it is suggested to attach a weight to the back of the backsheet delivering a specified weight. This can be achieved by means of gluing to the backsheet, with glue that maintains adhesion strength greater than that of the mechanical stresses applied. An approximation of realistic force direction (pull against shear) can be achieved by putting the modules at an angle into the environmental chamber (see Fig. 3). This may present a problem for test houses, where modules are mounted vertically in the chamber. Other approaches where similar force distributions are achieved are possible, but for the sake of simplicity the angled-mounting strategy is used here. The angle suggested is $45^{\circ}$ simply because it applies shear and pull forces in equal measures. The angle is somewhat steeper than what the majority of modules will see, as large power systems will be typically installed around $20^{\circ}$ inclination. However, domestic roof top installations will be in this range and thus the suggested inclination is not unreasonable.

Various weights are attached to the back of the devices under test (DUT) in this study in order to determine stress levels required. The stress needs to be sufficient to discriminate between good and bad samples without creating too many false negatives. The DUT is considered to have failed the test if any sagging of the weight is observed or any delamination is observed.

In order to validate this test, and to identify appropriate stress levels, the experiment reported below was conducted.

\section{EXPERIMENTAL DESIGN AND VALIDATION OF TEST APPROACH}

Bespoke samples were produced in-house at Centre for Renewable Energy Systems Technology (CREST), presenting a wide range of production conditions. The test is carried out on a small area, representative samples, simply for the sake of the number of samples to be tested simultaneously. This allows multiple stress levels and various module lamination conditions to be tested. A test to fail is carried out to identify appropriate stress levels.

Sample size is 12.5 by $20 \mathrm{~cm}$ with a glass-EVA-solar cellEVA-backsheet structure. No frames or sealants were used. All the materials are commercially available from the PV industry and widely used in the industry, but details cannot be released due to confidentiality. The glass front layer is $2.9 \mathrm{~mm}$ thick float glass. A fast cure EVA of a thickness of $460 \mu \mathrm{m}$ is used as an encapsulant. The backsheet is a tri-layer insulating polymer consisting of PET/PET/primer layer. The solar cells used are $1.8 \mathrm{~W}$ $\mathrm{mc}-\mathrm{Si}$ cells. These mini-modules were prepared under different lamination temperatures at $125,135,140,145$, and $150{ }^{\circ} \mathrm{C}$ with constant curing time of $10 \mathrm{~min}$. This introduces some conditions which are outside the production window and thus delivers some samples that should fail this test. These samples are referred to in the following as L125, L135, L140, L145, and L150, respectively. The measured gel content of the L125 samples was around $60 \%-70 \%$, which was the lowest. The gel content increases with the increasing lamination temperature and reached 91\% for L150 samples. All these samples are within specifications set for acceptable gel contents by the industry [18], albeit L125 is borderline.

The backsheet of each mini-module was prepared $5 \mathrm{~cm}$ longer than the module's length to enable easy attachment of a weight. Rather than gluing to the back, the actual weight was hung at the top part of the backsheet as shown in the left picture of Fig. 3. Different weights of $250 \mathrm{~g}, 500 \mathrm{~g}$, and $1 \mathrm{~kg}$ were used to stress the backsheet adhesion. For some samples, the top part of backsheet was cut into narrow strips of 1 or $2 \mathrm{~cm}$ wide for testing. This initial cut significantly increased the force per unit width, which was expected to lead to different failures. All the samples were mounted on a testing frame with $45^{\circ}$ tilted angle. This setup was then placed in an environmental chamber operating at $85{ }^{\circ} \mathrm{C} / 85 \% \mathrm{RH}$. The test is a $135^{\circ}$ peel test, which is close to conditions seen in the field. All samples were subjected to test to fail. The time when the delamination occurred was recorded for each sample and used as an indicator of the quality of module packaging.

The gravity test is to investigate the adhesion failures at the weakest interface of packaging materials under stressed condition that modules may encounter during the operation of their lifetime. The melting point of EVA is around $60-70{ }^{\circ} \mathrm{C}$, which means the EVA may be in different phases at room condition and at operating temperature [19]. This increases the likelihood of different failures being identified by the two testing approaches, i.e., the peel test and the gravity test. The other difference between these two approaches is that the gravity test is a constant load testing, i.e., peeling at a constant force, whereas the peel test is a constant displacement testing, i.e., peeling at a constant rate. These differences demonstrate that the presented test is closer to realistic conditions than the peel test used in the laboratory. A summary of number of samples for each lamination condition that tested under different stress condition is given in Table I. At least two samples were tested for one condition in order to ensure the reproducibility of the test.

\section{RESULTS OF TRIAL RUNS}

\section{A. Observed Failure Categories}

The weakest interface of the packaging material changes over time, which leads to different failure modes at different stress 
TABLE I

NUMBER OF SAMPLES FOR GRAVITY TEST

\begin{tabular}{lccccc}
\hline \hline & $20 \mathrm{~g} / \mathrm{cm}$ & $40 \mathrm{~g} / \mathrm{cm}$ & $80 \mathrm{~g} / \mathrm{cm}$ & $500 \mathrm{~g} / \mathrm{cm}$ & $1 \mathrm{~kg} / \mathrm{cm}$ \\
\hline L125 & 2 & 2 & 2 & 2 & 2 \\
L135 & 4 & 4 & 2 & 2 & 2 \\
L140 & 2 & 4 & 2 & 2 & 2 \\
L145 & 4 & 4 & 2 & 2 & 2 \\
L150 & 4 & 4 & 2 & 2 & 2 \\
\hline
\end{tabular}

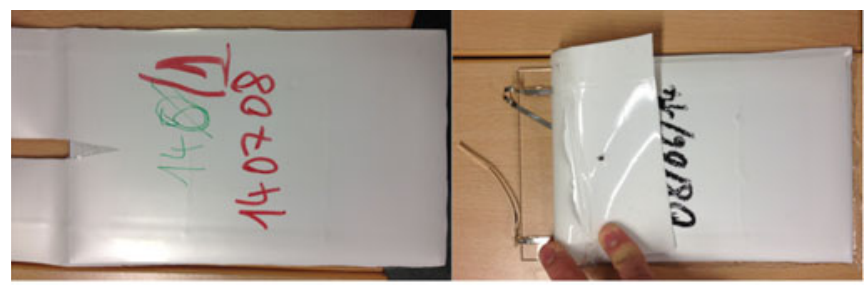

A

B

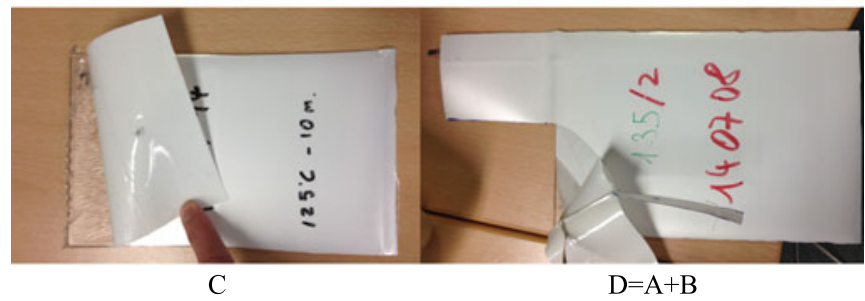

Fig. 4. Different types of failures of module packaging during the gravity test. (a) Delamination of backsheet sublayers. (b) Delamination between glass and EVA. (c) Delamination between EVA and backsheet. (d) Mixture of A and B.

TABLE II

SUMMARY OF FAILURE CATEGORIES FOR GRAVITY TEST

\begin{tabular}{lccccc}
\hline \hline & $20 \mathrm{~g} / \mathrm{cm}$ & $40 \mathrm{~g} / \mathrm{cm}$ & $80 \mathrm{~g} / \mathrm{cm}$ & $500 \mathrm{~g} / \mathrm{cm}$ & $1 \mathrm{~kg} / \mathrm{cm}$ \\
\hline L125 & $\mathrm{C}$ & $\mathrm{C}$ & $\mathrm{C}$ & $\mathrm{C}$ & $\mathrm{C}$ \\
$\mathrm{L} 135$ & $\mathrm{~A}$ & $\mathrm{~A}$ & $\mathrm{~B}$ & $\mathrm{AB}$ & $\mathrm{AB}$ \\
L140 & - & $\mathrm{A}$ & $\mathrm{B}$ & $\mathrm{A}$ & $\mathrm{A}$ \\
L145 & $\mathrm{A}$ & $\mathrm{AB}$ & $\mathrm{B}$ & $\mathrm{A}$ & $\mathrm{A}$ \\
L150 & $\mathrm{A}$ & $\mathrm{A}$ & $\mathrm{B}$ & $\mathrm{AB}$ & $\mathrm{AB}$ \\
\hline \hline
\end{tabular}

levels and times. Depending on the weight applied to backsheet, different failure modes were observed.

Fig. 4 shows the observed four different types of failures of module packaging during the gravity test. Type A failure is delamination of backsheet sublayers. Type B failure is delamination at the interface between glass and EVA. Type $\mathrm{C}$ failure is delamination at the interface between EVA and backsheet. Type D failure is a mix of Type A and Type B that delamination occurred at multiple layers including backsheet sublayer and between EVA and glass.

All tested samples delaminated eventually, except for the L140 sample with $20 \mathrm{~g} / \mathrm{cm}$ force which did not fail after $1800 \mathrm{~h}$ exposure. The observed delamination categories and times are summarized in Tables II and III, respectively.

L125 samples demonstrated from Type $\mathrm{C}$ delamination for all weights from 20 to $1000 \mathrm{~g} / \mathrm{cm}$ within $2 \mathrm{~h}$ of testing. This is due to the low curing temperature not being sufficient to
TABLE III

SUMMARY OF DELAMINATION TIME (HOURS)

\begin{tabular}{lccccc}
\hline \hline & $20 \mathrm{~g} / \mathrm{cm}$ & $40 \mathrm{~g} / \mathrm{cm}$ & $80 \mathrm{~g} / \mathrm{cm}$ & $500 \mathrm{~g} / \mathrm{cm}$ & $1 \mathrm{~kg} / \mathrm{cm}$ \\
\hline L125 & 2 & 2 & 2 & 2 & 1 \\
L135 & $1000 \pm 100$ & $175 \pm 25$ & 4 & 2 & 2 \\
L140 & $>1800$ & $360 \pm 40$ & $8 \pm 2$ & 2 & 2 \\
L145 & $1630 \pm 50$ & $300 \pm 60$ & 2 & 2 & 2 \\
L150 & $800 \pm 50$ & $25 \pm 5$ & 3 & 2 & 2 \\
\hline \hline
\end{tabular}

achieve diffusion of EVA and the EVA compatible material in the inner side of backsheet. Therefore, the EVA/backsheet interface remains the weakest interface.

For lamination temperature higher than $135{ }^{\circ} \mathrm{C}$, no Type C delamination was observed. Type B failure was seen by L135 to L150 samples tested with a weight of $80 \mathrm{~g} / \mathrm{cm}$. All failures occurred within $10 \mathrm{~h}$ of testing, indicating that the load is too heavy and is creating unrealistically short failure rates. Furthermore, the adhesion between glass and EVA was lower than that between EVA and backsheet $\left(\boldsymbol{f}_{g e}<\boldsymbol{f}_{e b}\right)$. The backsheet interlayer adhesions outperformed the adhesion at glass/EVA interface $\left(\boldsymbol{f}_{b s}>\boldsymbol{f}_{g e}\right)$. The quick delamination did not allow enough time for further degradation of the bulk materials of samples during the damp-heat test.

When applying a lighter weight of 20 or $40 \mathrm{~g} / \mathrm{cm}, \mathrm{L} 135-\mathrm{L} 150$ samples presented Type A failure at the backsheet sublayers in most cases. The lower weights applied to the sample backsheet allowed a relative longer period of time (up to $\sim 1600 \mathrm{~h}$ ) before delamination happened. During this time, the adhesion between glass and EVA surpassed the adhesion between backsheet sublayers $\left(\boldsymbol{f}_{g e}>\boldsymbol{f}_{b s}\right)$, which shifted the delamination from Type B to Type A. The primary factor might be that adhesion between backsheet sublayers degraded faster than the adhesion at other interfaces. This is quite likely as the DH condition tests the effect of humidity ingress through the backsheet and the interfaces within the backsheet sublayers would be the first to be affected and see faster moisture ingress and higher water vapor level.

The samples with a load larger or equal to $80 \mathrm{~g} / \mathrm{cm}$ delaminated in less than $10 \mathrm{~h}$. This demonstrates these weights are too high for adhesion testing. These forces are also not experienced for prolonged periods in the field, and thus this confirms the expectation that this is overtesting the samples. These forces are only experienced during events of misuse. The L135 and L150 samples presented a mix of Type A and Type B failures, which indicate that the adhesion at backsheet sublayers and the adhesion at glass/EVA interface were comparable $\left(\boldsymbol{f}_{g e} \approx \boldsymbol{f}_{b s}\right)$. The L140 and L145 samples, which are around the manufacturer's recommended optimum lamination temperature, saw Type A failure only.

The lowest load of $20 \mathrm{~g} / \mathrm{cm}$, which would also represent loading induced, for example, by the weight of the junction box. The time-to-fail also demonstrates a good ability to discriminate between good and bad laminations. The "good" laminations L135, L140, and L145 all survived the standard 1000 hours DH test. Thus, the recommendation is to add this weight during DH testing, ensuring that both pull and sheer forces around 
TABLE IV

Summary of FaILure CATEgories For PeEl Test

\begin{tabular}{ccccc}
\hline \hline & $0 \mathrm{~h}$ & $500 \mathrm{~h}$ & $1000 \mathrm{~h}$ & $1500 \mathrm{~h}$ \\
\hline L125 & C & BC & BC & BC \\
L135 & B & B & BC & BC \\
L145 & B & B & BC & BC \\
\hline \hline
\end{tabular}

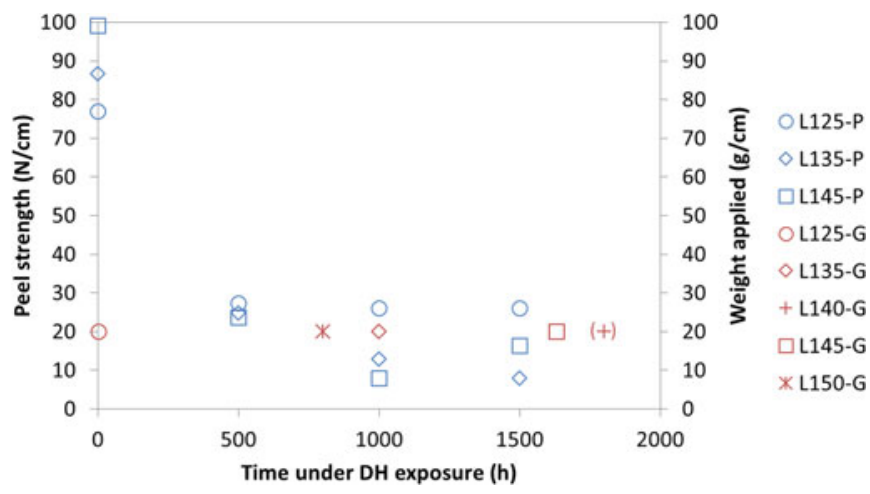

Fig. 5. Comparison between gravity test $(\mathrm{G})$ and peel test $(\mathrm{P})$.

$10-20 \mathrm{~g} / \mathrm{cm}$ are present. As an aside, this indicates that adding weights equivalent to $5 \mathrm{~N}$ onto the junction box as currently being discussed to test the adhesion of the junction box, may inadvertently introduce a delamination in dependence of where the weights are attached and if a pull force is exerted.

\section{B. Comparison With Peel Test}

The gravity test outcomes are compared with the standard peel test. It is shown that the outcomes are more realistic.

A different set of L125, L135, and L145 samples was subjected to DH exposure at $85{ }^{\circ} \mathrm{C} / 85 \% \mathrm{RH}$ for up to $1500 \mathrm{~h}$. Samples were removed from exposure after 500,1000, and $1500 \mathrm{~h}$ and tested for $90^{\circ}$ peel strength test with a crosshead speed of $50 \mathrm{~mm} / \mathrm{min}$ as described in [20]. Failure modes observed in peel tests conducted at room are summarized in Table IV. Although all the samples were prepared with the peeling interface at the glass/EVA interface, the L125 samples saw initial Type C failure between EVA and backsheet due to low mutual diffusion of EVA molecules. This changed to a mix of Type $\mathrm{B}$ and $\mathrm{C}$ failures after $500 \mathrm{~h}$ aging. The L135 and L145 samples saw Type B failure at glass/EVA interface at initial stage $(0-500 \mathrm{~h})$ and the failure shifted to the EVA/backsheet interface as samples aged. The pattern of failure modes summarized in Table III is different from the ones observed for the gravity test as shown in Table II. The peel test cannot test the adhesion at backsheet sublayers.

Fig. 5 plots the measured peel strength values against exposure time by peel tests together with the gravity test result of samples' time-to-failure (exposure time) with their corresponding weights $(20 \mathrm{~g} / \mathrm{cm})$ as the second $Y$-axis. L140 sample did not fail after $1800 \mathrm{~h}$ exposure, which is plotted in the brackets. The required peel strength decreases with the increasing exposure time. Looking at the L125-P and L125-G result, the gravity test was performed at a higher temperature and saw L125 samples failed quickly. In contrast, the peel test was performed at room temperature and L125 samples showed good durability in terms of adhesion. L125 is outside the permissible production window for a reason as modules are unlikely to have a reliable encapsulation and are likely to have delamination. Thus, these samples should not pass delamination tests and peel tests result might be misleading. This demonstrates that the proposed test is better at discriminating and identifying samples with delamination potential.

Peel tests show a rapid degradation in the early stages of $\mathrm{DH}$ exposure. The absolute difference between the different samples is relatively low with the results being within measurement uncertainty. At least that is the most likely interpretation of the increase of peel test adhesion for the $1500 \mathrm{~h}$ data point of the L145. The in situ test seems to give more useful information as it allows a measurable distinction between the different conditions.

\section{CONCLUSION}

The current certification tests do not appropriately pick up delamination while this is something seen in the field. This paper presented and verified that delamination is currently assessed by means of peel testing at conditions that are different than those seen during module operation. An in situ gravimetric test is developed that more reliably identifies potential delamination risks. It is shown that observed failures match those seen in reality much closer than the conventional T-peel test.

The gravimetric test applies a mix of shear and pull forces to a module's backsheet during standard damp-heat testing. Selecting appropriate weights allows an assessment as part of the conventional $1000 \mathrm{~h}$ damp-heat test. Failure is defined as delamination during the damp-heat test. In this paper, an identified appropriate stress level would be to attach a weight of $20 \mathrm{~g} / \mathrm{cm}$ to the backsheet with an equal distribution of pull and shear stresses. This is not too dissimilar to what would be expected from forces being applied by some junction boxes.

Clearly, there is potential to optimize this test further. However, it is shown that inappropriate lamination conditions will be identified by this test and thus the suggested test allows differentiation between reliable models and those at risk of delamination.

The suggested test would not add further tests in a certification cycle as it could be conducted in conjunction with certification tests commonly being done. Thus, at virtually no additional cost or effort, the risk of installations to delaminate can be reduced drastically.

\section{REFERENCES}

[1] G. Kleiss, J. Kirchner, and K. Reichart, "Quality and reliabilitysometimes the customer wants more," in Proc. NREL PV Module Rel. Workshop, Denver, CO, USA, p. 760, 2015.

[2] F. J. Pern and S. H. Click, "Adhesion strength study of EVA encapsulants on glass substrates," NREL, Denver, CO, USA, Tech. Rep. NREL/CP520-33558, Mar. 2003.

[3] F. J. Pern and G. J. Jorgensen, "Enhanced adhesion of EVA laminates to primed glass substrates subjected to damp heat exposure," in Proc. 31st IEEE Photovolt. Spec. Conf., Lake Buena Vista, FL, USA, Jan. 2005, pp. 495-498. 
[4] G. J. Jorgensen et al., "Moisture transport, adhesion, and corrosion protection of PV module packaging materials," Sol. Energy Mater. Sol. Cells, vol 90, pp. 2739-2775, 2006.

[5] A. W. Czanderna and F. J. Pern, "Encapsulation of PV modules using ethylene vinyl acetate copolymer as a pottant: A critical review," Sol. Energy Mater. Sol. Cells, vol. 43, pp. 101-108, 1996.

[6] M. A. Quintana, D. L. King, T. J. McMahon, and C. R. Osterwald, "Commonly observed degradation in field-aged photovoltaic modules," in Proc. 29th IEEE Photovolt. Spec. Conf., New Orleans, LA, USA, 2002, pp. 1436-1439.

[7] W. J. Gambogi et al., "Backsheet and module durability and performance and comparison of accelerated testing to long term fielded modules," in Proc. 28th Eur. Photovolt. Sol. Energy Conf. Exhib., Paris, France, 2013, pp. 2846-2850.

[8] D. DeGraaff, R. Lacerda, and Z. Campeau, "Degradation mechanisms in Si module technologies observed in the field; their analysis and statistics," NREL, Denver, CO, USA, Tech. Rep. NREL/TP-5200-60170, 2011.

[9] P. Sanchez-Friera, M. Piliougine, J. Pelaez, J. Carretero, and M. Sidrach de Cardona, "Analysis of degradation mechanisms of crystalline silicon PV modules after 12 years of operation in Southern Europe," Prog. Photovolt., Res. Appl., vol. 19, pp. 658-666, 2011.

[10] D. Polverini, M. Field, E. Dunlop, and W. Zaaiman, "Polycrystalline silicon PV modules performance and degradation over 20 years," Prog. Photovolt., Res. Appl., vol. 21, pp. 1004-1015, 2012.

[11] D. Wu, J. Zhu, D. Montiel-Chicharro, T. R. Betts, and R. Gottschalg, "Influences of different lamination conditions on the reliability of encapsulation of PV modules," in Proc. 29th Eur. Photovolt. Solar Energy Conf., Amsterdam, The Netherlands, 2014, pp. 3415-3420.

[12] G. Jorgensen, K. Terwilliger, S. Glick, J. Pern, and T. McMahon, "Material testing for PV module encapsulation," NREL, Denver, CO, USA, Tech. Rep. NREL/CP-520-33578, May 2003.
[13] D. R. Moore, "An introduction to the special issue on peel testing," Int. J. Adhesion Adhesives, vol. 28, pp. 153-157, 2008.

[14] Standard Test Method for 90 Degree Peel Resistance of Adhesives, ASTM D6862-11, 2016.

[15] D. L. King, M. A. Quintana, J. A. Kratochvil, D. E. Ellibee, and B. R. Hansen, "Photovoltaic module performance and durability following longterm field exposure," Progress Photovolt., Res. Appl., vol. 8, pp. 241-256, 2000.

[16] R. Gottschalg, T. R. Betts, A. Eeles, S. R. Williams, and J. Zhu, "Influences on the energy delivery of thin film modules," Sol. Energy Mater. Sol. Cells, vol. 119, pp. 169-180, 2013.

[17] L. Mei et al., "Equilibrium thermal characteristics of a building integrated photovoltaic tiled roof," Sol. Energy, vol. 83, pp. 1893-1901, 2009.

[18] A. Preiss, S. Krauter, M. Schoppa, and I. Luck, "PV module testing - how to ensure quality after PV module certification," Photovolt. Int., vol. 13 , pp. 166-176, Aug. 2011.

[19] D. C. Miller, M. D. Kempe, S. H. Glick, and S. R. Kurtz, "Creep in photovoltaic modules: Examining the stability of polymeric materials and components," in Proc. 35th IEEE Photovoltaic Spec. Conf., Honolulu, HI, USA, 2010, pp. 262-268.

[20] D. Wu, J. Zhu, T. R. Betts, and R. Gottschalg, "Degradation of interfacial adhesion strength within photovoltaic mini-modules during damp-heat exposure," Prog. Photovolt., Res. Appl., vol. 22, pp. 796-809, 2014.

Authors' photographs and biographies not available at the time of publication. 